\title{
Study regarding the improvement of the postage transport system in the city of Sibiu
}

\author{
Liliana Georgeta Popescu ${ }^{1 *}$, and Ovidiu Ioan Moldovan ${ }^{2}$ \\ ${ }^{1}$ Lucian Blaga University of Sibiu, Industrial Engineering and Management Department, 550025, \\ Victoriei, no.10, Sibiu, Romania \\ ${ }^{2}$ Conexiuni Association, Sibiu, Romania
}

\begin{abstract}
This paper presents a study on the improvement of postal system in the city of Sibiu where there are a number of three post offices that serve a number of eight counters, to which are added the distribution point and the collection point. Each post office has a well-established work schedule that differs from one office to another. The transport of postal items between the counters / post offices within the municipality of Sibiu and the collection office, must be done on a certain route, in order to respect the work schedule of each office and to take into account a number of restriction factors. In order to streamline the process of collecting and distributing postal items in Sibiu, 6 routes have been proposed and studied for the two shifts of drivers. With the help of the GeoMedia software, various route variants were calculated in terms of distance in kilometers, fuel consummation and time traveled. With the help of a spreadsheet calculation performed in Microsoft Office Excel, it was possible to check and recalculate the proposed routes, by entering the times that drivers spend loading and unloading postal items from each counter. It was thus possible to create a calculation sheet that can improve postal transport in Sibiu, and can increase the quality of services.
\end{abstract}

\section{Introduction}

The postal transport network means the multitude of postal transport connections having a permanent character on the geographical territory. The distribution and delivery of postal items rank among the primary operations of every company providing postal services. As a result, the costs of postal item distribution and delivery represent a major part of total costs and if these costs were reduced, significant savings could be accomplished. [1] The sharp decline in letter-post volumes led postal service providers to redesign their business models and rethink service delivery strategies, in compliance with national regulations.[2] But, in the post and mail operation, delivering mails on time is a very critical issue. Daily, post offices needs to operate millions of mails to be delivered on time.[3]

By postal connection is meant the existence of at least one postal route with a determined schedule, which connects two points on the network ensuring the transport of items between two points. On the postal network, the connections between two points are established either

\footnotetext{
*Corresponding author: liliana.popescu@ulbsibiu.ro
} 
directly or through other points and hence the names of direct links or through transits (indirect links).

The transport of a postal shipment between the point of dispatch and the point of destination (which are two points of the network) is done on an indirect link which can be seen as a sum of direct links between the consecutive points on the destination considered.

The postal link depends qualitatively on a large number of parameters, the most important of which are: distance covered, speed, number of items, safety factor, number of adjacent links, number of intermediate points, and frequency of connection. The effective realization of the postal connections is done with the help of the postal routes by going through some well-established itineraries and with a precise schedule between the points of the network.

\section{Case study}

In Sibiu there are a number of 3 post offices that serve a number of 8 counters. To these is added the distribution point - which operates in the building of the Post Office No. 1 and the collection point. Each post office has a well-established work schedule that differs from one office to another. The parcels, warrants and other services offered by the Romanian Post (newspaper deliveries, pensions, registered mail, etc.) - which will be hereinafter referred to generically as "merchandise" - are picked up every morning from Monday to Friday at 6.00 am from the Post Office 1 and transported with the machines provided at the post offices, respectively at the post offices in order to distribute them to the recipients. The "goods" taken over by the operators of the counters or post offices are distributed in the neighborhoods rounded to them, during the same day, by the postal factors.

As there are counters whose schedule differs on Monday / Wednesday / Friday from Tuesday and Thursday or which open their doors later, there is the problem of implementing an optimal route, so that the car / cars that distribute the "goods" in the morning (newspapers, parcels, letters, recommended, etc.) to travel the shortest route, but at the same time the fastest, taking into account the following factors:

- Working hours of the counters / post offices;

- The quantity of packages to be distributed (in case of large quantities, a high-capacity vehicle - will start racing);

- Road category and tonnage restrictions on certain routes;

- Traffic;

- The vehicle must not pass through the same point twice.

Table 1. Opening hours with the public of the post offices in Sibiu

\begin{tabular}{|c|c|}
\hline Postal Office & Work program \\
\hline Centralized Post Office & $8: 00-19: 00$ \\
\hline Post office 9 & $8: 00-19: 00$ \\
\hline Post office 6 & $8: 00-19: 00$ \\
\hline Post office 1-Counter 2 & $8: 00-14: 30$ \\
\hline Post office 6- Counter 1 & $8: 00-18: 00$ \\
\hline Post office 6- Counter 2 & $8: 00-18: 00$ \\
\hline Post office 6- Counter 3 & $8: 00-18: 00$ \\
\hline Post office 9- Counter 1 & $\begin{array}{c}\text { Monday / Wednesday / Friday:8:00-14:30 } \\
\text { Tuesday/ Thursday:11:00-18:00 }\end{array}$ \\
\hline Post office 9- Counter 2 & 9:00-18:00 \\
\hline Post office 9- Counter 3 & $\begin{array}{c}\text { Monday / Wednesday / Friday: 8:00-14:30 } \\
\text { Tuesday/ Thursday:11:00-18:00 }\end{array}$ \\
\hline Post office 1- Counter 1 & 10:30-18:00 \\
\hline Collection point & $6: 00-19: 00$ \\
\hline
\end{tabular}


Also, parcels, letters, etc. that are handed over by senders to post offices or in mailboxes for sending, must be collected twice a day (at 14:30 and at 18:00) from each post office and handed over at the collection office located in Sibiu Railway Station. These will be sorted and sent to the Regional Directorate in Brasov.

The route that the vehicles must take in the afternoon must take into account first of all the operating schedule (some counters close at 14:30, others at 18:00 or 19:00).

\subsection{Methodology}

The purpose of a Geographic Information System (GIS) is to provide an objective support for decisionmaking based on spatial data. [4] With the development of computer technology, Geographic Information Systems (GIS) are becoming popular tools for transportation analysis and planning. [5] A GIS is an organized collection of computer hardware, software, geographic data,and personnel designed to efficiently capture, store, update, manipulate, analyze, and display many forms of geographically referenced information. [6] Berglund (2001) contend that GIS integrates two parallel development paths: the spatial perspective; and the transport planning and modelling perspective. [7] GeoMedia provides fast, smart, and easier-to-use capture and editing tools than any functionality in traditional GIS systems. These tools allow the organization to manage its most important asset - the spatial data for the creation and collection of which so many resources have been consumed. By using GeoMedia Professional, you can make simultaneous real-time connections between geospatial data in various storage locations, analyze data relationships, turn data into accurate and ready-made maps for distribution and presentation. [8,9]

The coordinate points used are:

- Northwest: $\quad 45^{\circ} 47^{\prime} 34.5^{\prime \prime} \mathrm{N} 24^{\circ} 06^{\prime} 47.3^{\prime \prime} \mathrm{E}$

- Northeast: $\quad 45^{\circ} 47^{\prime} 35.4^{\prime \prime} \mathrm{N} 24^{\circ} 12^{\prime} 03.8^{\prime \prime} \mathrm{E}$

- Nord: $\quad 45^{\circ} 49^{\prime} 08.7^{\prime \prime} \mathrm{N} 24^{\circ} 09^{\prime} 23.0^{\prime \prime} \mathrm{E}$

\subsection{Creating framing paths in GeoMedia Professional}

The framing route is that route which is characterized by the start of the work shift, the vehicle leaves the collection point (Railway Station), passes by all post offices to collect all items and returns to the collection point (Railway Station). Currently, the collection of postal items in Sibiu is done according to Figure 1.

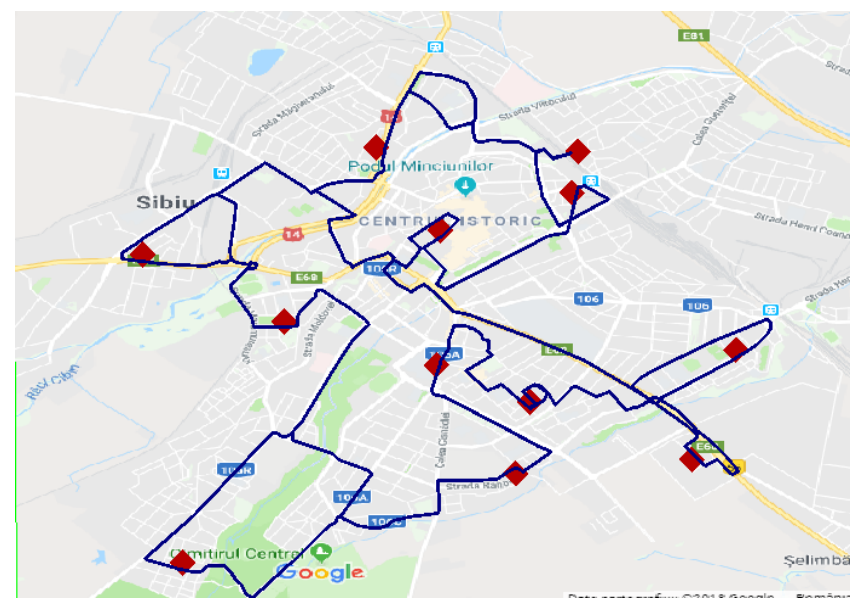

Fig. 1. Postal collection route 
The transport takes place twice a day, during each shift, which leads to fuel consumption and time lost in traffic. The route traveled by a car on the exchange is 42.42 kilometers (Figure 2)

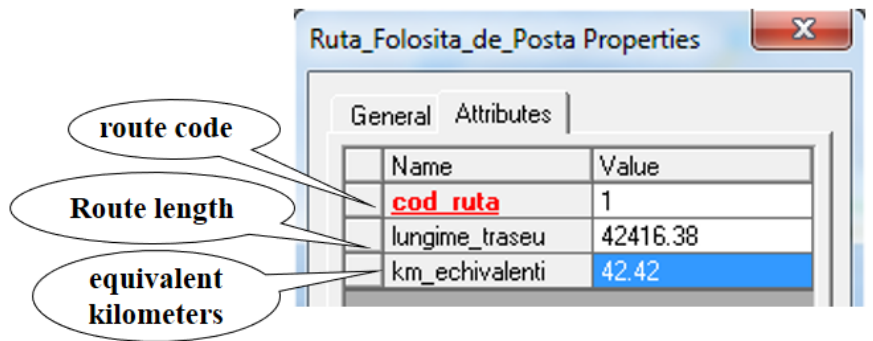

Fig. 2. Kilometers equivalent to the transport route

In order to streamline the process of collecting and distributing postal items in Sibiu, several route variants are proposed, following which an optimal route will be adopted based on the calculations. In order to facilitate the analysis of the routes in Sibiu, in a first stage the post offices were numbered. For this purpose, 6 framing routes were studied. Each route must have a circular one, which means that the vehicle starts from the collection point (Sibiu Railway Station, numbered 2) and returns to the final destination also in Sibiu Railway Station. The collection and distribution will be done according to the program of the post offices/counters, program presented in Table 1.

Framing route 1 (Figure 3), Route 2 (Figure 4) and Route 3 (Figure 5) takes place in exchange for one job. The vehicle starts from the collection point (Sibiu Railway Station) numbered with (2) and the destination Railway Station.

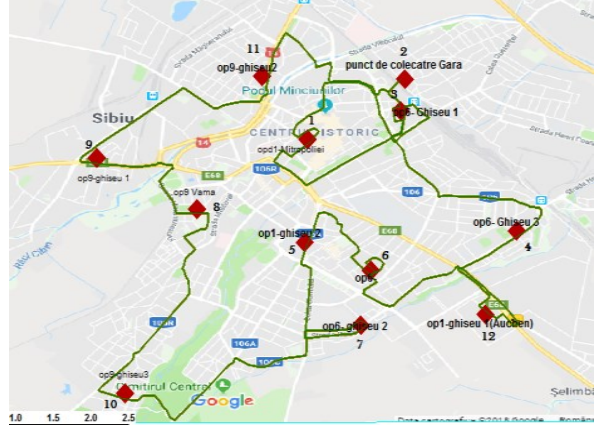

Fig. 3. Route 1 framing

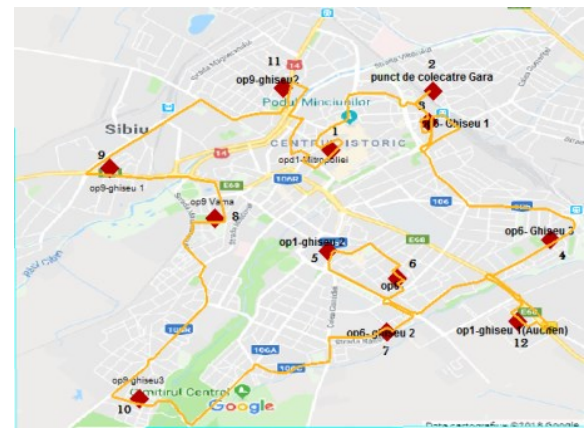

Fig. 5. Route 3 framing

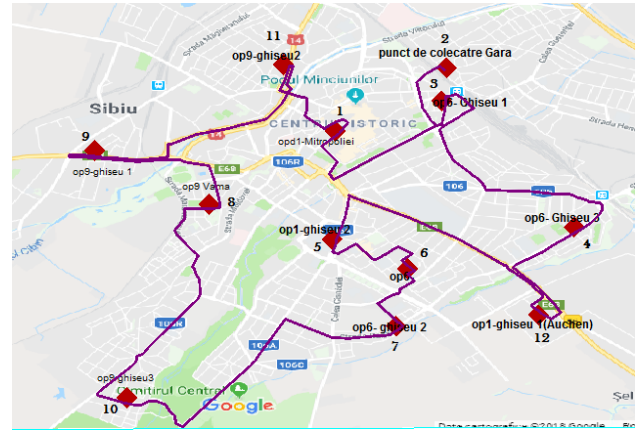

Fig. 4. Route 2 framing

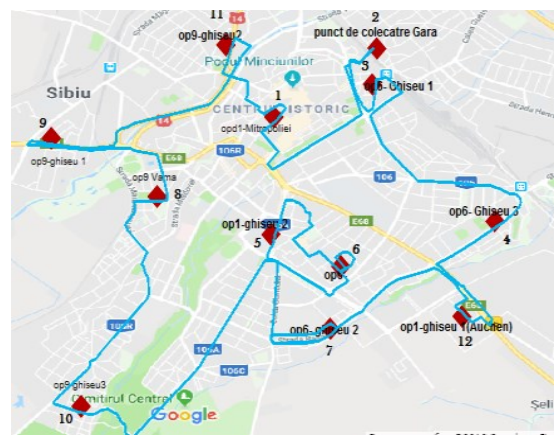

Fig. 6. Route 4 framing 


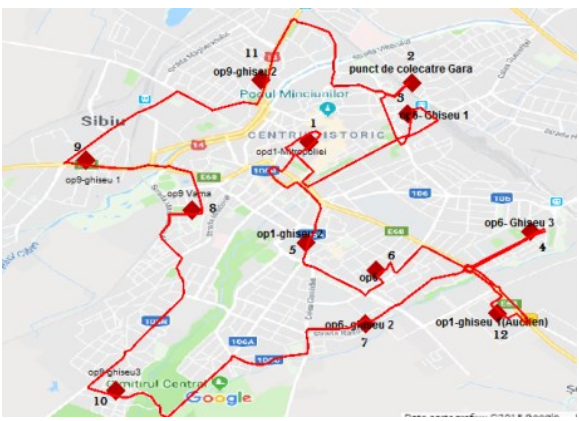

Fig. 7. Route 5 framing

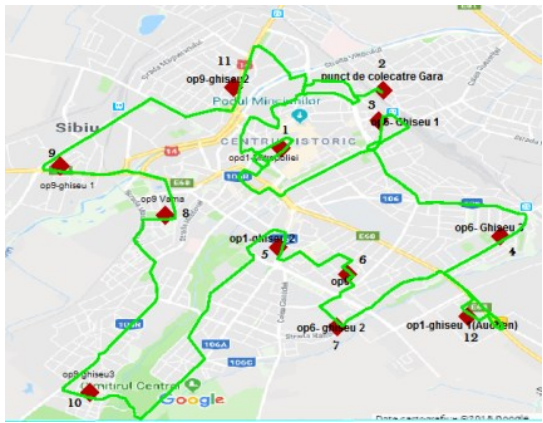

Fig. 8. Route 6 framing

Route 4 (Figure 6), route 5 (Figure 7) and route 6 (Figure 8), of classification takes place in the second shift of work. The vehicle starts from the collection point (Sibiu Railway Station) numbered 2 and returns to the same point.

\subsection{Calculation of framing path lengths}

Using the GeoMedia software you can determine the length of an entity drawn in a class that can be done automatically due to the georeferencing of the image according to the previously chosen coordinate points.[10] Thus, the distance of a route was automatically calculated (measured) by accessing the "update attributes" function from the "Edit" menu, introducing a length operator inside the corresponding attribute. The automatic measurement of the desired route length on the map resulted. (Figure 9)

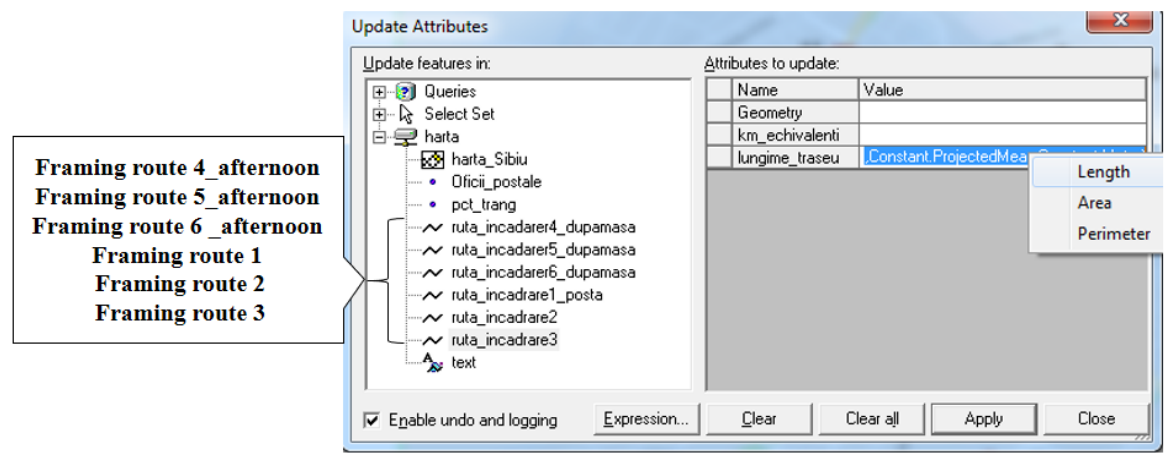

Fig. 9. Calculation of route lengths

Table 2 presents the centralized data resulting from the calculations performed in GeoMedia.

Table 2. Route length control

\begin{tabular}{|c|c|c|}
\hline No. & Route number & The length of the route \\
\hline 1. & ROUTE 1 & $36,404[\mathrm{~km}]$ \\
\hline 2. & ROUTE 2 & $29,975[\mathrm{~km}]$ \\
\hline 3. & ROUTE 3 & $31,935[\mathrm{~km}]$ \\
\hline 4. & ROUTE 4 & $35.091[\mathrm{~km}]$ \\
\hline 5. & ROUTE 5 & $32,795[\mathrm{~km}]$ \\
\hline 6. & ROUTE 6 & $34,993[\mathrm{~km}]$ \\
\hline
\end{tabular}


Taking into account the working hours of the post office 1 counter 1 (10:30-18:00), the post office 9 counter 3 (8: 00-14:30 Monday / Wednesday / Friday) and the post office 9 counter 1 (8:00-14:30 Monday / Wednesday / Friday) it can be concluded that the vehicle that leaves on routes 2 and 3 proposed, does not arrive in time at all post offices/ counters, and the car that leaves on routes 4-6 in exchange for 2 travels a greater number of kilometers than route 5 . In view of the above, it is proposed to carry out an analysis for routes 1 and 5 related to shift 1 and shift 2 of drivers. It should be noted that in shift 1 both the distribution of materials and the collection of postal items from each post office are performed, shift 1 performing practically a single collection from the post office 1 counter 1 . It is also proposed that in shift 2 no longer be done collection from the post office 1 counter 1 this activity being carried out before the closing of the office by the drivers of the exchange 1 .

As can be seen in Table 2, route 5 is the shortest in terms of kilometers traveled and includes all offices and post offices in the afternoon time. The study on fuel consumption, actual route length and operating times will be continued only for routes 1 and 5 .

\subsection{Calculation of fuel consumption within the classification routes}

In the vast majority of the fleet, the fuel used is diesel, so diesel consumption was calculated, because the vehicles on which the study was conducted have internal combustion engines on diesel.

\subsubsection{Framing of stroke 1 at the collection point}

The distance between the collection point - Sibiu Railway Station - and all the post offices to the final destination (which is represented by the same Sibiu Railway Station point) is 36,404 kilometers.

Taking into account the roads traveled by the vehicle, the road coefficient is 1.1 and the increase for urban traffic is 5 . The maximum number of stops on this distance is made at each post office (12), to which are added pedestrian crossings (29) and intersections without priority of passage (5). These number 34 . The increase for traffic in urban localities at the collection point (Railway Station) is:

The increase for traffic in urban localities is calculated by the relation (1):

$$
U=\frac{P v}{100} \times u[\mathrm{~km}]
$$

Where:

$\mathrm{U}$-sport for traffic in urban areas;

$\mathrm{Pv}$ - represents the actual journey of the car in urban areas;

$\mathrm{u}$ - the specific increase for traffic in urban localities;

The equivalent road distance is calculated by relation (2):

$$
P_{e d}=P \times i \times D \times i[\mathrm{~km}]
$$

Where:

Ped - the equivalent road course;

$\mathrm{P}$ - represents the actual course of the car;

D - road coefficient;

I - the category of the road

The equivalent path calculated using formula (3):

$$
P e=U+P_{e d}[k m]
$$

Where:

$\mathrm{Pe}$ - the equivalent course;

$\mathrm{U}$ - increase for traffic in urban areas; 
Ped - the equivalent route.

According to relation (4) the normal fuel consumption is:

$$
C n=\frac{P e}{100} \times C m \times A \times S_{b} \times Q \quad[\text { liters }]
$$

Where:

$\mathrm{Cn}$ - standard fuel consumption;

On the equivalent course;

$\mathrm{Cm}$ - average fuel consumption;

A - the correction coefficient;

$\mathrm{Sb}$ - the special correction coefficient;

$\mathrm{Q}$ - fuel increase.

The elapsed time is:

$$
T=\frac{P_{e} \times 60}{V m}[\text { minutes }]
$$

Where:

$\mathrm{T}$ - time traveled;

On the equivalent course;

Vm - average speed.

Applying the calculation relation (1) and (2), the number of equivalent kilometers is deduced for the distance traveled in the locality, respectively the distance traveled on different roads in Sibiu. The increase for traffic in urban localities at the collection point (Railway Station) is: 1,82 equivalent $\mathrm{km}$

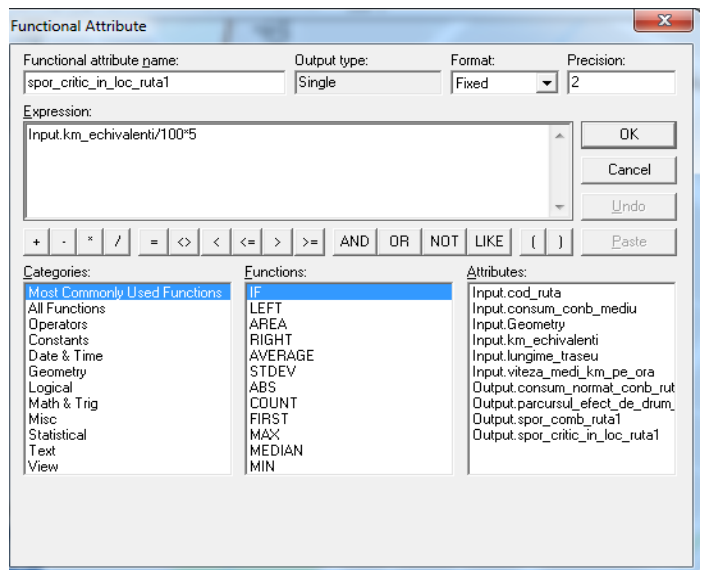

Fig.10. Calculation of the critical increase in the locality

The equivalent road distance from the current parking point is:

$$
P_{\text {ed }}=36.404 \times 1.1=40.04 \text { [equivalent } \mathrm{km} \text { ] }
$$

According to relation (4.3) the equivalent path from the current bus base is:

$$
P_{e}=1.82+40.04=41.86 \text { [equivalent } \mathrm{km} \text { ] }
$$

The increase in fuel consumption for stops and starts is determined by the relation: 


$$
Q=0.25 \times \frac{13.5}{100} \times 34=1.15 \text { [litri] }
$$

According to relation (4), the standard consumption on this distance is:

$$
\left.C n=\frac{40.04}{100} \times 13.5 \times 1 \times 1+0.84=6.80 \text { [liters }\right]
$$

According to relation (5) the time traveled on the route is:

$$
T=\frac{41,86 \times 60}{18}=139,55[\text { minutes }]
$$

The attributes of the framing route no.1 results are presented in Figure 11.

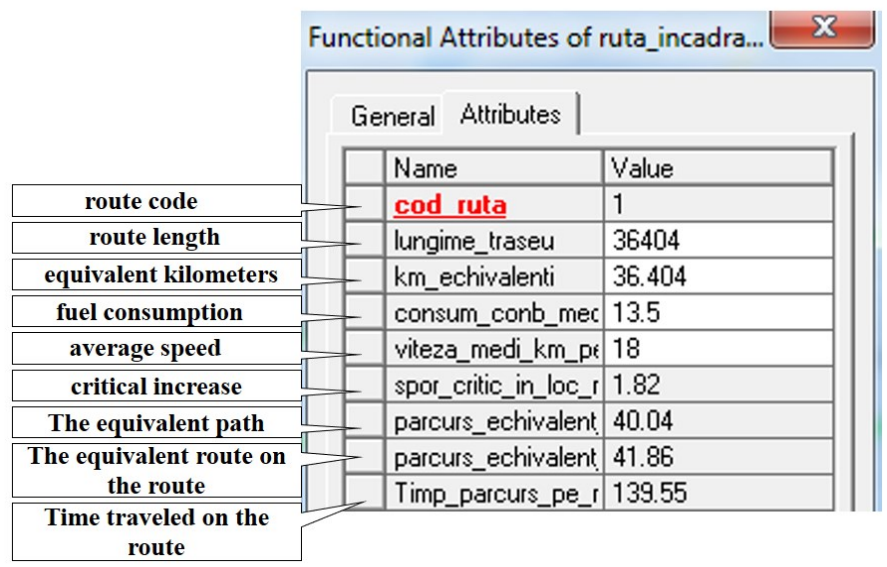

Fig. 11. Attributes of the classification route no.1

\subsubsection{Classification of route 5 from the collection point (Railway Station) to the destination}

The distance between the collection point (Railway Station) and all post offices to the final destination is 32,795 kilometers. The road coefficient, taking into account the roads traveled by the vehicle, is 1.1 , and the increase for urban traffic is 5 .

The maximum number of stops on this distance is 47 . These are the stops at each post office, pedestrian crossings and intersections without priority. In this case, the increase for traffic in urban areas at the collection point (Railway Station) is: 1.64 equivalent $\mathrm{km}$

The attributes of the framing path 5 are shown in Figure 12, and the results of the equivalent path are shown in Figure 13.

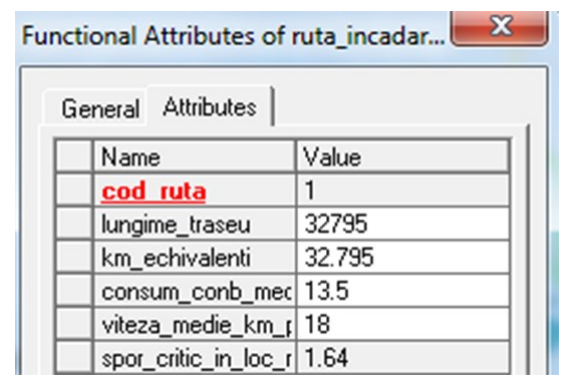

Fig. 12. Attributes of the classification route no.5 
The equivalent road distance from the current parking point is:

$$
P_{e d}=32.795 \times 1.1=36.07 \text { [equivalent } \mathrm{km} \text { ] }
$$

The equivalent route according to relation (3), is:

$$
P_{e}=1.64+36.07=37.71[\text { equivalent } \mathrm{km}]
$$

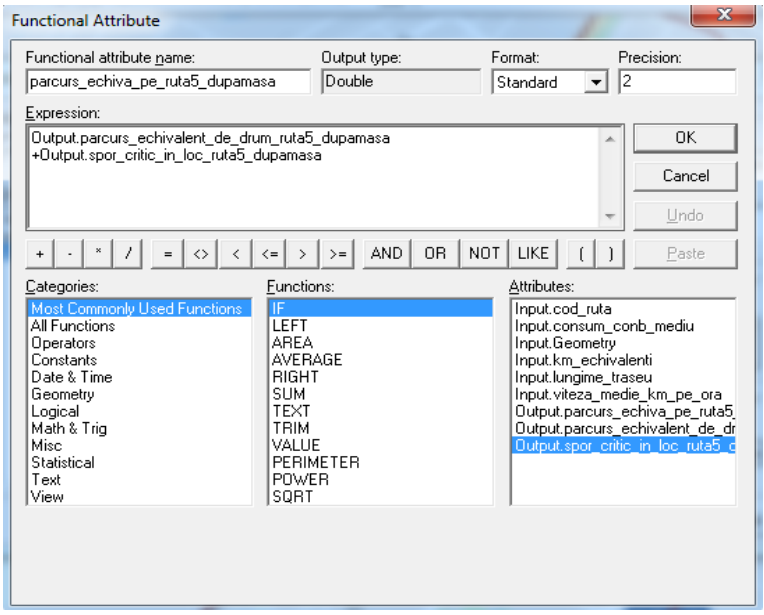

Fig. 13. The calculation formula of the equivalent route on route 5

The increase in fuel consumption for stops and starts is determined by the relation:

$$
Q=0.25 \times \frac{13.5}{100} \times 47=1.59[\text { liters }]
$$

According to relation (4.2.5), the standard consumption on this distance is:

$$
C n=\frac{40.04}{100} \times 13.5 \times 1 \times 1+0.84=6.51[\text { liters }]
$$

According to relation (12), the time traveled on the route is:

$$
T=\frac{37.71 \times 60}{18}=125,71[\text { minutes }]
$$

Using the Functional Attributes option in the GeoMedia application to perform the above calculations, an option that allows a series of queries, the data entered by the operator is displayed. The calculations made with the help of GeoMedia software are centralized in Table 3

Table 3. Centralizing the data related to route 1 and 5

\begin{tabular}{|l|l|l|l|}
\hline No & Parameters & ROUTE $\mathbf{1}$ & ROUTE 5 \\
\hline 1 & Increase for traffic in the locality & 1.82 equivalent $\mathrm{km}$ & 1.64 equivalent $\mathrm{km}$ \\
\hline 2 & The equivalent path & 40.04 equivalent $\mathrm{km}$ & 36.07 equivalent $\mathrm{km}$ \\
\hline 3 & The equivalent route on the route & 41.86 equivalent $\mathrm{km}$ & 37.71 equivalent $\mathrm{km}$ \\
\hline 4 & Increased fuel consumption & 1.15 liters & 1.59 liters \\
\hline 5 & Standard fuel consumption & 6.80 liters & 6.51 liters \\
\hline 6 & Standard fuel consumption & 139.55 minutes & 125.71 minutes \\
\hline
\end{tabular}




\subsection{Verification and recalculation of routes}

Based on the results obtained previously, it is proposed to implement a work program for drivers for the two shifts. For shift 1 (for the morning program), it is proposed to use route 1 and for the afternoon program it is proposed to use route 5 . The spreadsheets are made in Microsoft Excel and allow the calculation of departure and arrival times of vehicles at each office as well as the distance traveled. Figure 14 shows the calculation of a route considered to be the most efficient in terms of the number of kilometers traveled and the time traveled in traffic.

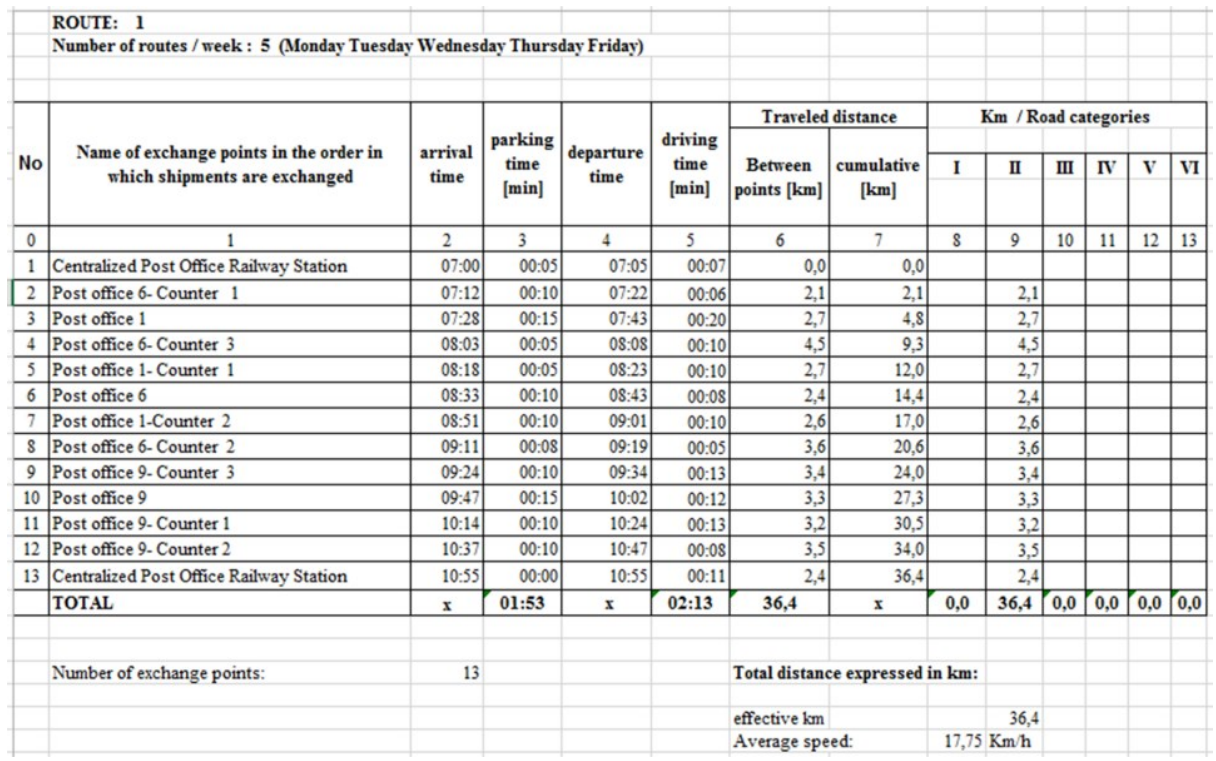

Fig.14. Spreadsheet - route 1

According to the calculation sheet presented in Figure 15, it results that route 5 is the most suitable for the second shift of drivers.

ROUTE: 5

Number of routes/week : 5 (Monday Tuesday Wednesday Thursday Friday)

\begin{tabular}{|c|c|c|c|c|c|c|c|c|c|c|c|c|c|c|}
\hline \multirow{3}{*}{ No } & \multirow{3}{*}{$\begin{array}{c}\text { Name of exchange points in the } \\
\text { order in which shipments are } \\
\text { exchanged }\end{array}$} & \multirow{3}{*}{$\begin{array}{c}\text { arrival } \\
\text { time }\end{array}$} & \multirow{3}{*}{$\begin{array}{l}\text { parking time } \\
\text { [min] }\end{array}$} & \multirow{3}{*}{$\begin{array}{l}\text { depart } \\
\text { ure } \\
\text { time }\end{array}$} & \multirow{3}{*}{$\begin{array}{l}\text { driving } \\
\text { time } \\
\text { [min] }\end{array}$} & \multicolumn{2}{|c|}{ Traveled distance } & \multicolumn{6}{|c|}{ Km / Road categories } & \multirow[b]{3}{*}{ VI } \\
\hline & & & & & & \multirow{2}{*}{\begin{tabular}{|c|} 
Between \\
points $[\mathrm{km}]$
\end{tabular}} & \multirow{2}{*}{$\begin{array}{c}\text { cumulati } \\
\text { ve }[\mathrm{km}]\end{array}$} & & & & & & & \\
\hline & & & & & & & & I & II & III & IV & $\mathbf{V}$ & VI & \\
\hline 0 & 1 & 2 & 3 & 4 & 5 & 6 & 7 & 8 & 9 & 10 & 11 & 12 & 13 & 14 \\
\hline 1 & Centralized Post Office Railway Station & $14: 00$ & $00: 15$ & $14: 15$ & $00: 00$ & 0,0 & 0,0 & & & 0,0 & & & & \\
\hline 2 & Post office 1-Counter 1 & $14: 15$ & $00: 05$ & $14: 20$ & $00: 10$ & 1,8 & 1,8 & & & 1,8 & & & & \\
\hline 3 & Post office 1 & $14: 30$ & $00: 20$ & $14: 50$ & $00: 20$ & 2,1 & 3,9 & & & 2,1 & & & & \\
\hline 4 & Post office 1- Counter 2 & $15: 10$ & $00: 10$ & $15: 20$ & $00: 22$ & 2,0 & 5,9 & & & 2,0 & & & & \\
\hline 5 & Post office 6 & $15: 42$ & $00: 15$ & $15: 57$ & $00: 08$ & 3,0 & 8,9 & & & 3,0 & & & & \\
\hline 6 & Post office 6 - Counter 1 & $16: 05$ & 00:09 & $16: 14$ & $00: 10$ & 2,6 & 11,5 & & & 2,6 & & & & \\
\hline 7 & Post office 1-Counter 1 & $16: 24$ & $00: 10$ & $16: 34$ & $00: 18$ & 2,5 & 14,0 & & & 2,5 & & & & \\
\hline 8 & Post office 6-Counter 2 & $16: 52$ & 00:07 & $16: 59$ & $00: 10$ & 2,6 & 16,6 & & & 2,6 & & & & \\
\hline 9 & Post office 9-Counter 3 & $17: 09$ & $00: 15$ & $17: 24$ & $00: 13$ & 3,2 & 19,8 & & & 3,2 & & & & \\
\hline 10 & Post office 9 & $17: 37$ & 00:17 & $17: 54$ & $00: 20$ & 3,9 & 23,7 & & & 3,9 & & & & \\
\hline 11 & Post office 9-Counter 1 & $18: 14$ & $00: 10$ & $18: 24$ & $00: 17$ & 3,0 & 26,7 & & & 3,0 & & & & \\
\hline 12 & Post office 9-Counter 2 & $18: 41$ & $00: 10$ & $18: 51$ & 00:09 & 3,2 & 29,9 & & & 3,2 & & & & \\
\hline \multirow[t]{2}{*}{13} & Centralized Post Office Railway Station & $19: 00$ & $00: 00$ & $19: 00$ & $00: 20$ & 2,8 & 32,7 & & & 2,8 & & & & \\
\hline & TOTAL & $\mathbf{x}$ & $02: 23$ & $\mathbf{x}$ & $02: 57$ & 32,7 & $\mathbf{x}$ & $\mathbf{x}$ & 0,0 & 32,7 & 0,0 & 0,0 & 0,0 & 0,0 \\
\hline & & & & & & & & & & & & & & \\
\hline & Number of exchange points: & 13 & & & & \multicolumn{3}{|c|}{ Total distance expressed in km: } & & & & & & \\
\hline & & & & & & & & & & & & & & \\
\hline & & & & & & effective $\mathrm{km}$ & & & & 32,7 & & & & \\
\hline & & & & & & Average speed: & & & & $11,08 \mathrm{k}$ & & & & \\
\hline
\end{tabular}

Fig. 15. Spreadsheet - route 5 
In the effort to improve operational performance, indicators such as reduce costs and increase productivity are some of the ways of measuring outcome. [11]

\section{Conclusions}

In the paper, the GeoMedia was applied to optimise the distribution routes of the postage transportation in the city of Sibiu. With the help of the GeoMedia software, various route variants were calculated in terms of kilometers traveled, fuel consumed and route time. The route that is currently followed daily by a vehicle from the County Post Office in Sibiu amounts to 42.42 kilometers / daily change. There are two expedition exchanges every day. This method was used to design two new distribution routes that comply with all constraints of the problem and the total length of which is $6.02 \mathrm{~km}$ shorter than in case of original distribution routes for the morning distribution and $9.71 \mathrm{~km}$ shorter than in case of original distribution routes for the afternoon distribution. Also, the authors made a spreadsheet performed in Microsoft Office Excel, where the proposed courses were checked and recalculated. By introducing the times that drivers spend for loading and unloading postal items from each counter, a calculation sheet has been created that can be taken into account when improving postal transport in Sibiu.

Based on the amount of kilometers saved, which was achieved using the GeoMedia software in case of the post office in the city of Sibiu, we can conclude that the optimization of distribution routes for branch offices from big cities in Romania, may represent a way to achieve significant savings in total costs of the company.

\section{References}

1. J. Šedivý, J. Čejka, Transp. Res. Proc. 53, 252-257 (2021)

2. G. Bruno, M. Cavola, A. Diglio, C. Piccolo, E. Pipicelli, Util. Policy. 69 (2021)

3. H. Iberahim, H. Mazlinda, M.D. Marhainie, A. Nur Hidayah, Procedia Soc. Behav. Sci. 219, 330-337 (2016)

4. J. Taboada, J.M. Matías, M. Araújo, C. Ordóñez, Eng. Geol. 87, 75-84 (2006)

5. K.X. Tang, N. M. Waters, Prog Plann 64, 7-62 (2005)

6. ESRI Understanding GIS - the ARC/INFO method. GeoInformation International (1995) available at http://www.ciesin.org/docs/005-331/005-331.html

7. S. Berglund, GIS in Transport Modelling, (Royal Institute of Technology, Högskoletryckeriet, Stockholm, 2001)

8. M. Kanderske, T. Thielmann, Communication and the Public 4(2), 118-132 (2019)

9. S. Selvam, A.Manisha, J.Vidhya, S.Venkatramanan, GIS and Geostatistical Techniques for Groundwater Science, (Elsevier Inc. 2019)

10. L. M. Martínez, T. Eiró, Procedia Soc. Behav. Sci. 54 525-536 (2012)

11. Thessaloniki, Kaizen Definition and Principles in Brief: A Concept Tool for Employees Involvement, (2006), available at www.michailolidis.gr/pdf/KAIZEN08.pdf 